\title{
The Role of Leadership in Organisational Regeneration: Incident of School Improvement
}

\author{
Jacob M Selesho \\ Faculty of Management Sciences, Vaal University of Technology, \\ Vanderbijpark, South Africa \\ jacobs@vut.ac.za
}

Doi:10.5901/mjss.2014.v5n7p317

\begin{abstract}
In the schooling system there is still a perception with regard to the role of the school principals in facilitation change management. There is still some held belief that organisational modification can only yield results if lead by capable leaders. This paper reports on a study conducted at schools that were not performing prior to the leadership or principal change. The aim of the study was to assess the impact of the leadership change in the school renewal among the teaching staff. The present study of principals' influence in the schools renewal and reorganisation, to perform better in their respective academic duties, was conducted among nine high schools in the Free State province. Of these nine high schools, six of them have had a change in principals in the past two years. A total of 167 teaching staff were selected to participate in the study; from the sample size of 167 teaching staff, the response rate was 128 (76.2\%). In order to obtain a holistic view of the overall leadership influence on organisation renewal in the school system, a multifactor leadership questionnaire (MLQ) was used. As the methodological paradigm applied in this research is a survey method with the questionnaire constructed in the Likert-type approach, ranging from one to five, the study may be classified as quantitative research. Permission to conduct the study was requested from, and granted by the district management. Data analysis and interpretation were done using the interactive model of quantitative data analysis, which first involved sorting or sifting through the data and sequences. Data were analysed by descriptive statistics such as percentages and frequency. Findings of the study reveal that changes in the leadership brought about some new methods of supporting teamwork and the enthusiasm by the teachers to work hard. Trust, which the teachers had almost lost, was renewed through the appointment of the new principal. The study can finally confirm that, to a certain degree, change in the school leadership brings some organisational renewal, as the new leader motivated the majority of teachers. They felt that the new principal brought hope to the school, and for that matter, their commitment was renewed and they wanted to contribute more in the school environment.
\end{abstract}

Keywords: leadership, influence, reorganisation, renewal, commitment

\section{Introduction}

From 2009, the provincial department of education declared certain schools as underperforming schools. These schools were not performing according to the national or provincial department of education benchmark. In some of these schools, the learner numbers had dropped as parents had begun to lose confidence in the education system of public schooling, and teacher were demotivated as they were performing below the national and provincial benchmark. Accompanying this poor performance were organisational dysfunctions and a lack of monitoring and control in the affected schools. This led to a thought process on how to lead a change of the management process, and it was in this regard that a change in the principalship was seen as a strategic move.

All current school reform efforts aim to improve teaching and learning. However, there are huge differences in how this is achieved, some reforms, for example, attempt to improve all schools in a district, and the country, at the same time. It can be noted that other forms of reform attempt to influence the overall approach to teaching and learning within a school, but focus on one school at a specific time. Still others focus on innovative curricula (in science and mathematics, for example) and typically address one part of a school's program and aim for widespread implementation, while innovative approaches to instruction such as cooperative learning, hope to change teachers' practices one teacher at a time.

However, as different as these approaches to school reform are, they all depend on the influence and capacities of the principal for their success. The chance of any reform improving scholastic achievement is remote, unless district and school leaders agree with its purposes and appreciate what is required to make it work (Susanj \& Jakopec 2012). The principal must also, for example, be able to help his/her colleagues to understand how the externally-initiated reform might be integrated into school improvement efforts, provide the necessary supports for those whose practices must 
change, and win the cooperation and support of parents and others stakeholders. Therefore, "effective" or "successful" leadership is critical to school reform (Pare \& Tremblay 2007). Based on the scenario mentioned above, there was a need to understand the impact of leadership renewal. The aim of the current study is to build further on the knowledge base about impact leadership in the school renewal system.

\section{Conceptual Understanding of Leadership}

While it can be confirmed that idealised influence is also known as charisma, from the leadership perspective, it is for this reason that, according to Bono and Judge (2003), leaders are admired, respected, and trusted. While followers identify with and want to emulate their leaders. It is for this purpose that the current study intends to determine the leadership influence in the school or organisational renewal. Bass and Avolio (1994) describe inspirational leader as, "Transformational leaders behave in ways that motivate and inspire those around them by providing meaning and challenge to their followers' work.... The leader creates clearly communicated expectations that followers want to meet and also demonstrate commitment to goals and shared visions". Kark and Dijl (2007) described intellectual stimulation as "behavior that arouses strong follower emotions and identification with the leader". Bass and Avolio (1994) describe individual consideration as, "Transformational leaders pay special attention to each individual's needs for achievement and growth by acting as a coach or mentor. Followers and colleagues are developed to successively higher levels of potential. New learning opportunities are created along with a supportive climate. Individual differences in terms of needs and desires are recognised. The leader's behaviour demonstrates acceptance of individual differences.

It cannot be contested that the quality of leadership is of importance; hence, the subject of leadership is interesting for many teaching staff. The continued search for good leaders has resulted in the development of many leadership theories. Studies have been carried out to determine how leadership behaviours can be used to influence employees for better organisational outcomes. Studies have concluded that effective leadership is associated with better and more performance as well a job satisfaction; hence, leadership behaviours is also found to be related positively to customer satisfaction (Pare \& Tremblay 2007; Chiok Foon Loke 2011; Baloch, Ali \& Zaman 2014). The use of leadership behaviours may be an important indirect contributor to customer delivery outcomes. The effective use of leadership behaviours is becoming a commitment for managers. Administrators desire it and consider it an important need for effective management. It is noted that in times of stress and chaos, leadership styles that transform create meaning in the midst of turmoil, and produce desirable employee outcomes (Chiok Foon Loke 2011), which are more beneficial for organisations' existence and performance.

Productivity and performance of an organisation depends upon the organisational commitment of its employees (Bushra, Usman \& Naveed 2011). Because leadership has been proposed as one of the most decisive factors contributing to the attitudes of employees toward their organisation (Bass, Avolio, Jung \& Berson 2003), it is probably among the most prominent predictors of organisational commitment. Findings of Ibrahim, Nurzahit, and Türker (2010) suggest that leadership has a substantial incremental effect on organisational commitment.

Leadership is defined as a process of interaction between leaders and followers in which leader attempts to influence followers in order to achieve a common goal (Kark \& Dijl 2007). Bass and Avolio (1994) proposed one of the new leadership theories, called the full-range leadership theory (FRLT). The constructs comprising the FRLT denote three typologies of leadership behaviour, transformational, transactional, and non-transactional laissez-faire leadership, which nine distinct factors represent.

Success in an organisation in terms of the attainment of goals and realisation of objectives depends on managers and their leadership influences. It is the belief of Van Der Viert (2006) that transformational leadership is vital to effective management, because the effectiveness of the leader determines the eventual success of the organisation. Transformational leaders are able to inspire followers to change their expectations, perceptions and motivations and to work towards common goals (Ibrahim, Nurzahit \& Türker 2010)

Transformational leaders are proactive; they improve follower awareness of transcendent, collective interests, and more importantly, they inspire followers to achieve extraordinary goals (Meyer, Allen \& Smith 1993).

The quality of a manager's relationship with an employee is the most powerful element of employee motivation. It creates a professional, positive and respectful attitude and employees are more likely to adopt a similar approach with their peers and enjoy work. It is clear that the management and leadership styles adopted by a business and its management will have a determining effect on the motivation level, the morale, and the job satisfaction of the employees (Ibrahim, Nurzahit \& Türker 2010). Nevertheless, the relationship between the management style used within the business, and the level of motivation within the workforce, is a subject of much debate within industry. In many circles, there is a continuous debate about whether leaders are born or developed. Reflecting on the discussions about 
motivation, it is evident that humans are very complicated and made up of a number of traits. With motivation, these influences are both inherited and acquired from our environment and influences (Gary 1996). It is in this regard that the study seeks to establish the role of leadership on employee motivation.

\section{Research Methodology}

\subsection{Participants}

The present study of principals' influence in the school renewal and reorganisation, to perform better in their respective academic duties, was conducted among nine high schools in the Free State province. From these nine high schools, six of them have had a change in principal within the past two years. A total of 167 teaching staff was selected to participate, and it should be noted that some of the reasons for the movement of principals from one school to another was based on the fact these high schools were not performing above the provincial benchmark. Teaching staff were selected to participate in this study because teaching is a core duty in this enterprise. More importantly, the study intended to assess the influence brought by the new principal regarding organisational renewal. The participants were selected conveniently; however, the sample was chosen in such a way that more participants came from schools that were not performing above the provincial benchmark. Of the nine high schools, 95 percent of them have performed at above 80 percent in the 2013 academic year. The data were obtained from the schools and all the teaching staff were encouraged to complete the questionnaire. The sample size was 167 teaching staff and the response rate was $128(76.2 \%)$. This response rate is regarded as good, and could be attributed to the fact that administrative clerks administered the questionnaires during schools hours.

\subsection{Data Collection Instrument}

Identifying similar phrases, relationships between themes, distinct differences between target blocks, and common selfadministered questionnaires containing structured items, were applied. Items in the questionnaire focused on the leadership styles and the role of leaders in the schools in assisting and supporting teaching staff. In addition, a question was asked on how the principal manages the school. Closed questions helped in eliciting specific information, while open-ended questions enabled the respondents to express their views freely and without restriction. In order to obtain a holistic view of the overall leadership style present in the school system, a MLQ was used (Mclaggan, Bezuidenhout \& Botha 2013). From the MLQ the researcher decided to use 12 items for the current study, and these were adapted from the original scale designed by Meyer, Allen and Smith (1993). As the methodological paradigm applied in this research is a survey method, with the questionnaire constructed in the Likert-type approach ranging from one to five, the study may be classified as quantitative research.

\subsection{Procedure}

Permission to conduct the study was requested and granted by the district management. The researcher personally administered the questionnaires with the assistance of schools' administrative clerks, and the research support group collected the completed questionnaires. Throughout the study, every effort was made to maintain high ethical standards. Anonymity and confidentiality were protected at all times, with a thorough explanation in the form of a covering letter, provided to all participants, detailing the purpose of the study. Data analysis and interpretation were done using the interactive model of quantitative data analysis (McMillan \& Schumacher 2010), which first involved sorting or sifting through the data and sequences.

\subsection{Data analyses}

After the return of all the questionnaires, it was important that the mass of data collected should then be reduced to a format suitable for analysis. The respondents' responses were then coded according to the emerging themes using the Statistical Package for Social Sciences (SPSS), version 20.0 for Microsoft Windows. Data were analysed by descriptive statistics such as percentages and frequency to test, among other things, the reliability of describing the impact and the leadership style in these schools. 


\section{Results and Discussions}

The study comprised 167 respondents of which a response rate of 128 was received. The results obtained from the empirical study will now be discussed according to the emerging themes from the variables stated in the literature.

The results below were analysed from the MLQs. The reporting in this paper will report only on five item questionnaires that relate management and leadership in schools.

Table 1: Enthusiasm to work harder

\begin{tabular}{|ll|c|c|c|c|}
\hline & & Frequency & Percent & Valid percent & Cumulative percent \\
\hline Valid & not at all & 12 & 7.2 & 9.4 & 9.4 \\
& once in a while & 7 & 4.2 & 5.5 & 14.8 \\
& Sometimes & 7 & 4.2 & 5.5 & 20.3 \\
& fairly often & 37 & 22.2 & 28.9 & 49.2 \\
& frequently if not always & 65 & 38.9 & 50.8 & 100.0 \\
& Total & 128 & 76.6 & 100.0 & \\
Missing & System & 39 & 23.4 & & \\
Total & 167 & 100.0 & & \\
\hline
\end{tabular}

From the analysis above, it is clear that the teachers were willing to work harder than before. Table 1 indicates that 50.8 percent of the teachers were willing to work harder just to satisfy the principal, as they were happy with his her leadership qualities. It can also be reported that 9.4 percent of the teachers were not at all willing to try to work harder, while 5.5 percent of the respondents sometimes entertained thoughts to work harder. Therefore, it could be concluded that the majority of the respondents took the initiative from the principal, particularly regarding the focus on support and encouragement to work harder, as well as the sense of hard work and professionalism.

Table 2: Team work

\begin{tabular}{|ll|c|c|c|c|}
\hline & Frequency & Percent & Valid percent & Cumulative percent \\
\hline Valid & not at all & 20 & 12.0 & 15.6 & 15.6 \\
& once in a while & 5 & 3.0 & 3.9 & 19.5 \\
& Sometimes & 12 & 7.2 & 9.4 & 28.9 \\
& fairly often & 41 & 24.6 & 32.0 & 60.9 \\
& frequently if not always & 50 & 29.9 & 39.1 & 100.0 \\
& Total & 128 & 76.6 & 100.0 & \\
Missing & System & 39 & 23.4 & & \\
Total & 167 & 100.0 & & \\
\hline
\end{tabular}

It is clear from Table 2 that the changes restored by the new leadership had some impact on the rebuilding and reorganisation process. The performance of the schools as well as the rating of the leadership from the respondents can equate this. From a total of 167 respondents, 23,4 percent did not return their questionnaires, while 39.1 percent were of the view that the principal always worked towards building teamwork in the school, 32 percent believe the principal is building teamwork to a fair degree, and 9.2 percent were of the opinion that the principal sometimes tried to build teamwork in the school. Of all the respondents 15.6 percent and 3.9 percent were of the view that at no time had the principal tried to build teamwork and once in a while tried to build teamwork, respectively. Therefore, the indication is that the majority of the respondents who responded to this question believe the principal is doing something in rebuilding the school. 
Table 3: Specifies the importance of having a strong sense of purpose

\begin{tabular}{|ll|c|c|c|c|}
\hline & Frequency & Percent & Valid percent & Cumulative percent \\
\hline Valid & not at all & 9 & 5.4 & 7.1 & 7.1 \\
& once in a while & 10 & 6.0 & 7.9 & 15.1 \\
& Sometimes & 21 & 12.6 & 16.7 & 31.7 \\
& fairly often & 39 & 23.4 & 31.0 & 62.7 \\
& frequently if not always & 47 & 28.1 & 37.3 & 100.0 \\
& Total & 126 & 75.4 & 100.0 & \\
Missing & System & 41 & 24.6 & & \\
Total & & 167 & 100.0 & & \\
\hline
\end{tabular}

Respondents from the above-mentioned question were in support of the principal leadership qualities. This can be confirmed in Table 3 by the positive response from the respondents answer, as 37.3 percent indicated that the principal is frequently, if not always, in support of promoting the value for purpose in the school. Nonetheless, 31 percent of the respondents stated that the principal had some discussion with them fairly often with regard to the sense of purpose to the school. Despite the fact that majority of the respondents were in support of the role of the principal in shaping the school and restoring the culture of a sense and belonging, some of the respondents did not interpret the questions in that manner. Almost 32 percent of the respondents were of the view that the principal is not providing direction; neither is he/she giving a sense of value, belonging or purpose for the school. More importantly, 32 percent of the respondents indicated that the principal is not providing support to their professional development.

Table 4: Effective representation to higher authority

\begin{tabular}{|ll|c|c|c|c|}
\hline & Frequency & Percent & Valid percent & Cumulative percent \\
\hline Valid & not at all & 13 & 7.8 & 10.2 & 10.2 \\
& once in a while & 4 & 2.4 & 3.1 & 13.3 \\
& Sometimes & 19 & 11.4 & 14.8 & 28.1 \\
& fairly often & 51 & 30.5 & 39.8 & 68.0 \\
& frequently if not always & 41 & 24.6 & 32.0 & 100.0 \\
& Total & 128 & 76.6 & 100.0 & \\
Missing & System & 39 & 23.4 & & \\
Total & & 167 & 100.0 & & \\
\hline
\end{tabular}

The majority of the respondents were of the view that the principal is representing the their school very well to the higher authority. It can be seen from Table 4 that 32 percent and 39.8 percent were confident that the principal is representing them very well in the higher authority, as needed. This were also proven by the respect that higher authority were begin to show to the schools as well as the space to given to the school for coming with their own initiative. As compared with the previous leadership, teachers were beginning to have a sense of trust in the system. However, some respondents were still reluctant to display their trust in the principal, as 13.3 percent were of the belief that they still do not have trust in the principal's representation to the higher authority. It can be concluded that an overwhelming majority trusted the representation of the principal to the higher authority at both the district level and provincial offices.

Table 5: Displays a sense of power and confidence

\begin{tabular}{|ll|c|c|c|c|}
\hline & Frequency & Percent & Valid percent & Cumulative percent \\
\hline Valid & not at all & 9 & 5.4 & 7.0 & 7.0 \\
& once in a while & 8 & 4.8 & 6.3 & 13.3 \\
& Sometimes & 18 & 10.8 & 14.1 & 27.3 \\
& fairly often & 45 & 26.9 & 35.2 & 62.5 \\
& frequently if not always & 48 & 28.7 & 37.5 & 100.0 \\
& Total & 128 & 76.6 & 100.0 & \\
Missing & System & 39 & 23.4 & & \\
Total & & 167 & 100.0 & & \\
\hline
\end{tabular}


From Table 4 it can be seen that the majority of the respondents were of the view that the principal is confident about turning the schools around. They believed that the principal is aware of the expectations from the teaching staff; hence, 37.5 percent and 35.2 percent responded that the principal is frequently, if not always, displaying a sense of power in his/her endeavours. The teaching staff were excited that the principal is restoring their confidence with regard to how they should perform and support the culture of teaching and learning at the school. On the other hand, 13.3 percent of the respondents were of the view that the principal does not display a sense of power and confidence in his/her job and leadership qualities.

Table 6: Leads a group that is effective

\begin{tabular}{|ll|c|c|c|c|}
\hline & Frequency & Percent & Valid percent & Cumulative percent \\
\hline Valid & not at all & 12 & 7.2 & 9.4 & 9.4 \\
& once in a while & 6 & 3.6 & 4.7 & 14.1 \\
& Sometimes & 10 & 6.0 & 7.8 & 21.9 \\
& fairly often & 46 & 27.5 & 35.9 & 57.8 \\
& frequently if not always & 54 & 32.3 & 42.2 & 100.0 \\
& Total & 128 & 76.6 & 100.0 & \\
Missing & System & 39 & 23.4 & & \\
Total & & 167 & 100.0 & & \\
\hline
\end{tabular}

It can be noted from Table 6 that it cannot be contested that the respondents were happy with the effectiveness of the leadership style of the principal in leading a group of teaching staff. From the total of 128 respondents, 54, 46 and 10 respondents respectively were of the view that the principal is doing more than enough to lead the team effectively. More importantly teachers were of the view that the leadership skill displayed by their principal was effective in ensuring that everybody is participating.

\section{Conclusion}

The concept of linking principal reshuffling, with improved performance in grade 12 results, was tested in the current study. This concept did not only focus on the improved performance, but paid particular attention to a number of factors that make an impact on the school functionality. Results of the study were analysed and the finding were presented above. The results were divided into six categories that focused on the principals' leadership quality that could instil the organisational renewal in the schools.

It is clear from the results that although the teaching staff might have been in the profession for a long time, and worked with many different leaders, they have confidence in the new leader. They were of the view that the new principal must be given the benefit of the doubt and, therefore, more support was afforded by the teaching staff.

The study can also report that the leaders brought some new methods of supporting teamwork and the enthusiasm to work hard, by the teachers. Teachers felt that their initiatives and hard work is being recognised more by the new leader than the previous one; hence, this reinforced their commitment. They trusted that the principal is representing them well with the higher authorities, as district and other officials were not frequenting the school as much as they did with the previous leader.

Finally, the study confirms that to a certain degree, change in the school leadership brings some organisational renewal, as majority of the teacher were prepared to work cooperatively with the new leader. They felt that the principal is bringing hope to the school and this renews their commitment and made them want to contribute more to the school.

\section{References}

Baloch, Q.B., Ali, N. \& Zaman, G. 2014. Measuring employee commitment as outcomes of transformational and transactional leadership style: empirical study. Abasyn Journal of Social Sciences, 3(2): 208-214.

Bass, B.M., \& Avolio, B.J. 1994. Improving organizational effectiveness through transformational leadership. Thousand Oaks, CA: Sage.

Bass, B.M., Avolio, B.J., Jung, D. I. \& Berson, Y. 2003. Predicting unit performance by assessing transformational and transactional leadership. Journal of Applied Psychology, 88(2): 207-218.

Bono, J. and T. Judge, 2003. Self-concordance at work: toward understanding the motivational effects of transformational leadership. Academy of Management Journal, 46: 554-571.

Bushra, F., Usman, A. \& Naveed, A. 2011. Effect of transformational leadership on employee job satisfaction and organizational 
commitment in banking sector of Lahore. International Journal of Business and Social Science, 2(18): 261-267.

Chiok Foon Loke, J. 2011. Measuring employee commitment as outcomes of transformational and transactional leadership style: empirical study. Journal of Nursing Management, 9(3): 191-204.

Gary, J. 1996. Theories of work motivation, leadership, organisational behaviour: understanding and managing life at work. Concordia University: Harper Collins College Publishers.

Ibrahim, S.M., Nurzahit, K., \& Türker, B. 2010. Leadership style and organisational commitment: Test of a theory in Turkish banking sector. Journal of Academic Research in Economics, 2(1): 1-20.

Kark, R. \& Dijl, D.V. 2007. Motivation to lead, motivation to follow: the role of the self-regulatory focus in leadership processes. Academy of Management Review, 32(2): 500-528.

Meyer, J.P., Allen, N.J. \& Smith, C.A. (1993). Commitment to organizations and occupations: extension and test of a three component conceptualization. Journal of Applied Psychology, 78(4): 538-551.

McMillan, J.H. \& Schumacher, S. 2010. Research in Education. New York: Pearson Education.

Mclaggan, E., Bezuidenhout, A. \& Botha, C.T. 2013. Leadership style and organisational commitment in the mining industry in Mpumalanga. South African Journal Human Resource Management, 11(1): 1-9.

Pare, G. \& Tremblay, M 2007. The influence of high-involvement human resource practices, procedural justice, organisational commitment, and citizenship behaviour on information technology professional' turnover intentions. Journal of Group and Organisation Management, 32(3): 326-357.

Susanj, Z. \& Jakopec, A. 2012. Fairness perception and job satisfaction as mediators of relationship between leadership style and organisational commitment. Journal of Physchological Topics, 21(3): 509-526.

Van Der Viert, E. 2006. Autocratic leadership around the globe: do climate and wealth drive leadership culture. Journal of Cross-Cultural Psychology, 37(1): 42-59. 